\title{
Dynamic physiological responses to the incremental shuttle walk test in adults
}

\section{Respostas fisiológicas no incremental shuttle walk test em adultos}

\author{
Evandro Fornias Sperandio, Ricardo Luís Fernandes Guerra, Victor Zuniga Dourado*
}

Universidade Federal de São Paulo (Unifesp), Santos, SP, Brazil

\begin{abstract}
Introduction: Understanding the normal dynamic physiological responses to the incremental shuttle walk test might enhance the interpretation of walking performance in clinical settings. Objective: To assess dynamic physiological responses to the incremental shuttle walk test and its predictors in healthy adults. Methods: We assessed the simultaneous rates of changes of $\Delta$ oxygen uptake/ $\Delta$ walking velocity $\left(\Delta \mathrm{VO}_{2} /\right.$ $\Delta \mathrm{WV}), \Delta$ heart rate/ $\Delta$ oxygen uptake $\left(\Delta \mathrm{HR} / \Delta \mathrm{VO}_{2}\right), \Delta$ ventilation/ $\Delta$ carbon dioxide production $\left(\Delta \mathrm{VE} / \Delta \mathrm{VCO}_{2}\right)$, and $\Delta$ tidal volume/ $\Delta$ linearized ventilation $(\Delta \mathrm{VT} / \Delta \mathrm{lnVE})$ during the incremental shuttle walk test in 100 men and women older than 40 years. Fat and lean body masses (bioimpedance) were also evaluated. Results: We found that the dynamic relationships were not sex-dependent. Participants aged $\geq 70$ presented declines in $\Delta \mathrm{VO}_{2} / \Delta \mathrm{WV}$ slope compared to those aged 40-49 (215 \pm 69 vs. $288 \pm 84 \mathrm{~mL} \cdot \mathrm{min}^{-1} . \mathrm{km}^{\mathrm{h}}{ }^{\mathrm{h}}$ ). Obese participants presented shallower slopes for $\Delta \mathrm{VO}_{2} / \Delta \mathrm{WV}(2.94 \pm 0.90$ vs. $3.84 \pm 1.21$ mL.min-1.kg-1.km.h-1) and $\Delta \mathrm{VT} /$ $\Delta \operatorname{lnVE}(0.57 \pm 0.20$ vs. $0.67 \pm 0.26)$. We found negative influence of fat body mass on $\Delta \mathrm{VT} / \Delta \ln V E\left(\mathrm{R}^{2}=0.20\right)$ and positive influence of lean body mass on $\Delta \mathrm{VO}_{2} / \Delta \mathrm{WV}\left(\mathrm{R}^{2}=0.31\right), \Delta \mathrm{HR} / \Delta \mathrm{VO} 2\left(\mathrm{R}^{2}=0.25\right)$, and $\Delta \mathrm{VT} / \Delta \operatorname{lnVE}$ $\left(\mathrm{R}^{2}=0.44\right)$. Conclusion: Dynamic relationships during walking were slightly influenced by age, but not sex-dependent. Body composition played an important role in these indices. Our results may provide better interpretation of walking performance in patients with chronic diseases.
\end{abstract}

Keywords: Exercise. Walking. Physical Fitness.

\footnotetext{
* EFS: PhD, e-mail: evandrosperandio@yahoo.com RLFG: PhD, e-mail: ricoguerra06@yahoo.com.br VZD: PhD, e-mail:vzdourado@yahoo.com.br
} 
Resumo

Introdução: Compreender as respostas fisiológicas dinâmicas normais ao incremental shuttle walk test pode melhorar a interpretação do desempenho da caminhada em ambientes clínicos. Objetivo: Avaliar as respostas fisiológicas dinâmicas em detrimento do incremental shuttle walk test e seus preditores em adultos saudáveis.

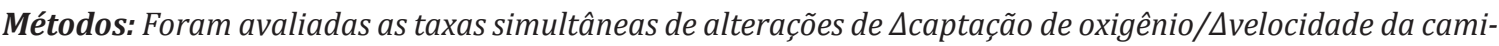

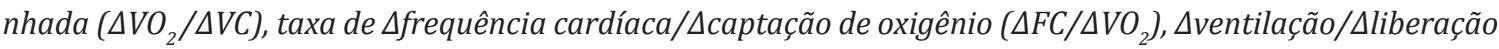
de gás carbônico $\left(\triangle V E / \Delta V C O_{2}\right)$, e o $\Delta$ volume corrente/Aventilação linearizada $(\triangle V C / \Delta \operatorname{lnVE})$ durante o incremental shuttle walk test em 100 homens e mulheres com mais de 40 anos. Massa gorda e a massa magra corporal (bioimpedância) também foram avaliadas. Resultados: Descobrimos que as relações dinâmicas não eram dependentes de sexo. Os participantes com idade $\geq 70$ apresentaram declínios na inclinação da relação $\Delta \mathrm{VO}_{2} / \Delta V \mathrm{C}$ em comparação com aqueles com idade entre 40-49 (215 $\left.\pm 69 \mathrm{vs} 288 \pm 84 \mathrm{~mL} / \mathrm{min} / \mathrm{km} / \mathrm{h}\right)$. Os par-

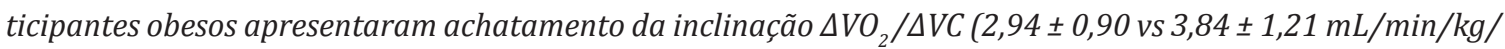
$\mathrm{km} / \mathrm{h})$ e $\triangle V C / \Delta \ln V E(0,57 \pm 0,20$ vs 0,67 $\pm 0,26)$. Encontramos influência negativa da massa gorda corporal em $\Delta V C / \Delta \ln V E\left(R^{2}=0,20\right)$ e a influência positiva da massa magra corporal sobre $\Delta V O_{2} / \Delta V C\left(R^{2}=0,31\right), \Delta F C / \Delta V O_{2}$ $\left(R^{2}=0,25\right)$, e $\Delta V C / \Delta \ln V E\left(R^{2}=0,44\right)$. Conclusão: Relações dinâmicas durante a caminhada foram ligeiramente influenciada pela idade, mas não pelo sexo. Já a composição corporal desempenhou um papel importante nesses índices. Nossos resultados podem proporcionar uma melhor interpretação do desempenho da caminhada em pacientes com doenças crônicas.

Palavras-chave: Exercício. Caminhada. Aptidão Física.

\section{Introduction}

The cardiopulmonary exercise test (CPET) offers the opportunity to appreciate precisely the complex interaction among musculoskeletal, cardiovascular and respiratory systems in a controlled environment (1). The peak physiological values obtained in an incremental protocol are generally used as indices of cardiorespiratory fitness. Among these variables, peak oxygen uptake (peak $\mathrm{VO}_{2}$ ) and $\mathrm{VO}_{2}$ obtained at lactate threshold are the most commonly used indices (2).

Although the peak variables is valuable, the consideration of a single value for the variables of interest may be unsuitable as a frame of reference for interpreting continuous dynamic physiological responses to the CPET. Moreover, the interpretation of the dynamic relations does not require maximum effort, because the trend has a linear behavior. Thus, the dynamic relationships can be used in submaximal physical tests. This strategy makes it possible to improve the interpretation of physical fitness both in patients and in healthy people. Furthermore, submaximal tests can be performed by any nonphysician healthcare professionals able to do so. The dynamic relationships such as $\Delta$ oxygen uptake/
$\Delta$ work load $(\Delta \mathrm{V} 02 / \Delta \mathrm{W}), \Delta$ heart rate $/ \Delta$ oxygen uptake $(\Delta \mathrm{HR} / \Delta \mathrm{VO} 2), \Delta$ ventilation $/ \Delta$ carbon dioxide production $(\Delta \mathrm{VE} / \Delta \mathrm{VCO} 2)$ and $\Delta$ tidal volume/ $\Delta$ linearized ventilation relationship $(\Delta \mathrm{VT} / \Delta \ln V E)$ may improve the interpretation of exercise capacity (3). For example, the shallower rate changes in $\Delta \mathrm{VO} 2 / \Delta \mathrm{W}$ may indicate problems of mechanical efficiency. Similarly, a marked increase in slope of the $\Delta \mathrm{HR} / \Delta \mathrm{VO} 2$ relationship may indirectly indicate cardiac abnormalities or peripheral muscle incapacity to use the oxygen. A steeper increase in $\Delta \mathrm{VE} / \triangle \mathrm{VCO} 2$ relationship indicates hyperventilation, increased dead space of breathing, or both. In addition, lower values of $\Delta \mathrm{VT} / \Delta \ln V E$ relationship translate a tachypneic breathing pattern (4). To analyze these dynamic relationships properly, a rapidly incremental exercise protocol is required (3).

Walking is the most popular form of physical activity among middle-aged and older adults. It has also been widely used as a method of assessing functional exercise capacity in in patients with chronic diseases as well as in asymptomatic individuals (5-7). The incremental shuttle walk test (ISWT) was developed in the 90s in order to evaluate patients with respiratory diseases. This test is performed with a speed 
increase every minute imposed by audio signals until exhaustion. The normal peak physiological responses to the ISWT were recently described in adults older than 40 years (8). There is scarce information on dynamic physiological responses during walking. Considering that the ISWT is a rapidly incremental walking test, it would be possible to perform the dynamic physiological analysis during this test. This knowledge might be useful for better interpretation of walking performance in middle-aged and older adults with or without chronic diseases. We therefore assessed the dynamic physiological responses to the ISWT and checked the age- and sex-related changes in physiological responses to the ISWT. In addition, we verified the association between the main physiological variables and body composition in adults older than 40 years old.

\section{Methods}

Participants

One hundred participants were selected voluntarily for the present cross-sectional study. Inclusion criteria for this study were: be male or female aged 40 years old or above and being free from cardiovascular, respiratory, metabolic, neuromuscular or musculoskeletal affections. Exclusion criteria were: having orthopedic problems, recent respiratory infections, unstable or stable angina in the last four weeks, recent myocardial infarction, angioplasty or cardiac surgery in the last three months. Individuals with abnormal spirometry, defined as forced expiratory volume in the $1^{\text {st }}$ second $\left(\mathrm{FEV}_{1}\right)$ to forced vital capacity (FVC) ratio $<70 \%$, as well as $\mathrm{FEV}_{1}$ and $\mathrm{FVC}<80 \%$ of the predicted values (9), with a BMI above of $35 \mathrm{~kg} / \mathrm{m}^{2}$ and with high levels of habitual physical activity (assessed by questionnaire) and current smokers were also excluded. The volunteers were recruited through dissemination in social networks, folders displayed in the universities of the region, local magazines and newspapers. The participants were informed about the possible risks and discomforts of the procedures proposed in the present study and signed a consent form. The Ethic Committee for Research in Humans of the Federal University of São Paulo (UNIFESP) approved this study by the protocol 186.796 .
Protocol

Potential participants underwent a series of evaluations over the course of mornings of two days spaced within seven days of each other. On day 1 individuals: completed a physical activity readiness questionnaire (10), a face-to-face interview regarding history of respiratory diseases based on the American Thoracic Society (ATS) questionnaire (11); and cardiovascular disease (CVD) risk stratification was performed according to the American College of Sports Medicine (ACSM) (12). We investigated the presence of self-reported major risk factors for CVD, including age (male $\geq 45$ years; female $\geq 55$ years); family history of premature coronary heart disease (CHD) (definite myocardial infarction before 55 years old in father or 65 years old in mother or other first-degree relative); systemic arterial hypertension; diabetes; dyslipidemia and current cigarette smoking; and a questionnaire on physical activity (13). They also performed spirometry, and measurements of anthropometry and body composition. Those who met the eligibility criteria returned on day 2 and held three ISWT with 20 min apart.

We classified participants as sedentary by questionnaire according to the American College of Sports Medicine recommendations (i.e., 30 minutes/day, 5 days/wk of at least moderate-to-vigorous physical activity) (14). Participants were asked about the time spent in exercise activities per day and per week and the type and intensity of physical activities so that we could exclude those involved in very vigorous physical activities.

\section{Anthropometry and body composition}

Body mass ( $\mathrm{kg}$ ) and height $(\mathrm{m})$ were measured following a standardized technique with participants using light clothes and without shoes. Body mass was measured to the nearest $0.1 \mathrm{~kg}$ in a portable digital scale (TBF 310GS, Tanita, Arlington Heights, IL, USA) and height was determined to the nearest $0.5 \mathrm{~cm}$ with a portable stadiometer (Wood, WCS, Curitiba, PR, Brazil). The BMI was then calculated (kg.m $\left.{ }^{-2}\right)$. Body composition was assessed in a subsample of 69 participants ( 38 females; $59 \pm 10$ years), using the same portable scale provided by a bioelectrical impedance system following the procedure described by Kyle et al. (15). The lean body mass (LBM) and fat body mass 
(FBM) were calculated using the regression equations developed for healthy individuals (16).

\section{Spirometry}

Spirometry was performed using a hand-held spirometer (Spiropalm; COSMED, Pavona di Albano, Italy) according to the criteria established by the American Thoracic Society (17). FEV, FVC and $\mathrm{FEV}_{1} / \mathrm{FVC}$ were quantified. In order to calculate the predicted spirometric variables, Brazilian reference values (18) were used.

\section{Incremental shuttle walk test}

The ISWT was conducted in a 10-m long hallway at a progressive speed (increased by $0.17 \mathrm{~m} / \mathrm{s} \mathrm{ev-}$ ery minute). The walking speed was controlled by a series of sounds indicating the moment the subject should change directions around the cone. Every 60 $\mathrm{s}$, another sound indicated the moment at which the subject should increase the pace. The test was terminated when the patient indicated that he was unable to continue or the operator assessed that the patient was unable to sustain the speed and cover the distance to the cone prior to the beep sounding. This was defined as the patient being $0.5 \mathrm{~m}$ away from the cone when the bleep sounds on a second successive $10-\mathrm{m}$ length. When the patients were just 0.5-m outside of the mark, they were advised to increase their speed of walking; if the patient fails to do so then the test was terminated and the distance recorded. Furthermore, standardized verbal commands were given to the participants, as recommended (19). When the subject was unable to reach the closest cone (i.e. was $>0.5 \mathrm{~m}$ from the cone) by the time the signal sounded, the rater ended the test, which could also be terminated by the subject for any reason. Dyspnea and leg fatigue were quantified before and after each test. Three tests were performed with at least 20 minutes of rest among each of them. A new test was initiated only if the blood pressure, heart rate and perceived exertion had returned to baseline values. The incremental shuttle walk distance (ISWD) in meters obtained in the third test was quantified and the walking velocity (WV), in $\mathrm{km} . \mathrm{h}^{-1}$, was registered every minute. The ISWT was developed to assess functional exercise capacity in patients with lung disease and its original protocol consists of 12 stages (total distance, $1.020 \mathrm{~m}$ ) (20). However, because we were applying the test in healthy subjects, we extended it to 15 stages $(1.500 \mathrm{~m})$, in order to avoid the ceiling effect. We kept adding $0.17 \mathrm{~m} / \mathrm{s}$ every minute beyond the $12^{\text {th }}$ stage, as other studies have made (21).

\section{Physiologic responses}

During the third ISWT, expired gases were collected through a mask and assessed by a portable telemetric gas analyzer $\left(\mathrm{K}_{4} \mathrm{~b}^{2}\right.$, Cosmed, Pavona di Albano, Italy). The participants breathed through a face mask with minimal dead space $(0.30 \mathrm{~mL})$. The gas analyzer with a total weight $<1 \mathrm{~kg}$ was attached on the trunk of the participants by straps over the shoulders, allowing free movement. The data were analyzed in a continuous on-line radio transmission and displayed on a personal computer located at one of the course extremities. The reference gas, $3 \mathrm{~L}$ syringe, and delay calibrations were performed following the manufacturer's recommendations. The metabolic, cardiovascular and ventilatory variables were analyzed breath by breath. All tests were performed under the same altitude, atmospheric pressure, and mild temperature. The following variables were emphasized: $\mathrm{VO}_{2}, \mathrm{VCO}_{2}, \mathrm{HR}, \mathrm{VT}$, and VE. Data were filtered every $15 \mathrm{~s}$ and the arithmetic mean of the variables was used for assessing dynamic physiological relationships for each participant.

The simultaneous rates of change of key variables were determined according to described by Neder et al. (3): $\Delta V O 2 / \Delta W V\left(\mathrm{ml} \cdot \mathrm{min}^{-1} \cdot \mathrm{km} \cdot \mathrm{h}^{-1}\right.$ and $\mathrm{ml} \cdot \mathrm{min}^{-1}$. $\mathrm{kg}^{-1} \cdot \mathrm{km} \cdot \mathrm{h}^{-1}$ ) to characterize the mechanical efficiency; $\Delta \mathrm{HR} / \Delta \mathrm{VO} 2$ (beat.min ${ }^{-1}$.L. $\mathrm{min}^{-1}$ ) as a cardiovascular efficiency; $\Delta V E / \Delta V C O 2\left(\right.$ L.min $^{-1}$.L.min ${ }^{-1}$ ) as a ventilatory efficiency, and $\Delta \mathrm{VT} / \Delta \operatorname{lnVE}$ to characterize the breathing pattern. Such dynamic relationships were obtained by simple linear regressions and the values of the slope coefficient of the central trend line generated by the equation was submitted to analysis.

\section{Statistical analysis}

The sample size calculation was based on sex-related differences observed in the study by Neder at al. (3). Initially, we calculate the sex-related standardized 
magnitude of the effect (SME = magnitude of the effect/outcome standard deviation) for submaximal relations, considering the alpha at 0.05 and beta at 0.80 . We note that the relationship with greater variability and lower magnitude of effect was the $\triangle \mathrm{VE} / \triangle \mathrm{VCO} 2$ with SME $=0.8(2 / 2.5)$. We obtained the minimum value of 26 participants in each group. As for multiple regression analysis, we considered 15 observations for each predictor included in the model, which resulted in at least 60 participants (age, sex, height, and sex).

Data were evaluated descriptively and are presented as mean \pm standard deviation. The sex-related differences of the main physiological variables were firstly evaluated using the Student t test or Mann-Whitney test, and two-way analysis of variance (ANOVA) was used to determine differences among age groups (i.e., 40-49, 50-59, 60-69, and $\geq 70$ years) and possible interactions with sex. Bivariate correlations were assessed by Pearson or Spearman coefficients depending on the distribution of data and the size of the correlation coefficients were classified as follows: .00 to $.30=$ negligible; .30 to $.50=$ low; .50 to $.70=$ moderate; .70 to $.90=$ high; .90 to $1.00=$ very high (22).

A series of enter multiple regression analysis equations were developed using the main dynamic physiological responses as dependent variables. Multiple regression models were adjusted by age, body mass, height and sex. Multicollinearity was assessed before stating the regression procedures. The alpha error for all tests was set at 5\%.

\section{Results}

One hundred participants (55 females, $60 \pm 10$ years) composed the sample of the present study (Table 1).

Table 1 - General characteristics and peak values of the key physiological variables during the incremental shuttle walk test according to sex

\begin{tabular}{lcc}
\hline \multicolumn{2}{c}{ Sex } \\
\hline & $\begin{array}{c}\text { Females } \\
(\mathrm{n}=55)\end{array}$ & $\begin{array}{c}\text { Males } \\
(\mathrm{n}=45)\end{array}$ \\
\hline Age $(\mathrm{yr})$ & $59 \pm 11$ & $59 \pm 9$ \\
Body mass $(\mathrm{kg})$ & $73 \pm 15$ & $80 \pm 12^{\star}$ \\
Height $(\mathrm{m})$ & $1.57 \pm 0.07$ & $1.71 \pm 0.07^{\star}$ \\
\hline
\end{tabular}

(To be continued)
(Conclusion)

Table 1 - General characteristics and peak values of the key physiological variables during the incremental shuttle walk test according to sex

\begin{tabular}{lcc}
\hline & \multicolumn{2}{c}{ Sex } \\
& $(\mathbf{n}=55)$ & Males \\
& $28 \pm 6=45)$ \\
\hline BMI $\left(\mathrm{kg} \cdot \mathrm{m}^{-1}\right)$ & $27 \pm 3^{*}$ \\
Peak V02 (mL.min-1) & $1422 \pm 330$ & $2203 \pm 594^{*}$ \\
Peak V02 (mL.min $\left.{ }^{-1} \cdot \mathrm{kg}^{-1}\right)$ & $20 \pm 5$ & $28 \pm 6^{*}$ \\
Peak HR (beats.min $\left.{ }^{-1}\right)$ & $135 \pm 21$ & $139 \pm 21$ \\
Peak HR (\% of maximum) & $81 \pm 11$ & $84 \pm 13$ \\
Peak VE (L.min $\left.{ }^{-1}\right)$ & $41 \pm 12$ & $65 \pm 20^{*}$ \\
Peak VT (L) & $1.316 \pm 0.323$ & $2.142 \pm 0.527^{*}$ \\
ISWD (m) & $446 \pm 128$ & $629 \pm 135^{*}$ \\
ISWD (\% of predicted) & $108 \pm 18$ & $110 \pm 19$ \\
Peak WV (km.h $\left.{ }^{-1}\right)$ & $5.90 \pm 0.75$ & $6.94 \pm 0.82^{*}$ \\
\hline
\end{tabular}

Note: ${ }^{*} p<0.05$ males vs. females; $\mathrm{BMI}=$ body mass index; VO2 = oxygen uptake; HR = heart rate; VE = minute ventilation; $\mathrm{VT}=$ tidal volume; ISWD = incremental shuttle walk distance; $\mathrm{WV}=$ walking velocity

The dynamic relationships were not sex-dependent (Table 2). We found a significant decline in $\Delta \mathrm{VO} 2 / \Delta \mathrm{WV}$ in participants aged $\geq 70$ compared to those aged 40-49 (Table 3) with no interactions with sex.

Obese participants $(n=30)$ presented shallower slopes for $\Delta \mathrm{VO}_{2} / \Delta \mathrm{WV}$ and $\Delta \mathrm{VT} / \Delta \ln V E$ as well as lower values of peak $\mathrm{VO}_{2}$ (Table 4 ). The $\Delta \mathrm{VT} / \Delta \ln V E$ relationship was negatively influenced by FBM and LBM presented positive influence on $\Delta \mathrm{VO}_{2} / \Delta \mathrm{WV}$, $\Delta \mathrm{HR} / \Delta \mathrm{VO}_{2}$, and $\Delta \mathrm{VT} / \Delta \mathrm{lnVE}$ relationships (Figure 1).

Table 2 - Dynamic physiologic responses to the incremental shuttle walk test according to sex

\begin{tabular}{|c|c|c|}
\hline & \multicolumn{2}{|c|}{ Sex } \\
\hline & $\begin{array}{l}\text { Females } \\
(n=55)\end{array}$ & $\begin{array}{c}\text { Males } \\
(n=45)\end{array}$ \\
\hline$\Delta \mathrm{V} 02 / \Delta \mathrm{WV}\left(\mathrm{mL} \cdot \mathrm{min}^{-1} \cdot \mathrm{km} \cdot \mathrm{h}^{-1}\right)$ & $258 \pm 68$ & $257 \pm 68$ \\
\hline$\Delta \mathrm{V} 02 / \Delta \mathrm{WV}\left(\mathrm{mL} \cdot \mathrm{min}^{-1} \cdot \mathrm{kg}^{-1} \cdot \mathrm{km} \cdot \mathrm{h}^{-1}\right)$ & $3.69 \pm 1.23$ & $3.32 \pm 1.11$ \\
\hline$\Delta \mathrm{HR} / \Delta \mathrm{VO2}$ (beat.min ${ }^{-1}$.L.min ${ }^{-1}$ ) & $40 \pm 12$ & $42 \pm 16$ \\
\hline$\Delta \mathrm{VE} / \Delta \mathrm{VCO} 2\left(\mathrm{~L} \cdot \mathrm{min}^{-1}\right.$.L. $\left.\mathrm{min}^{-1}\right)$ & $29 \pm 4$ & $28 \pm 4$ \\
\hline$\Delta \mathrm{VT} / \Delta \mathrm{lnVE}$ & $0.63 \pm 0.22$ & $0.65 \pm 0.27$ \\
\hline
\end{tabular}

Note: $\Delta \mathrm{VO} \mathrm{O}_{2} / \Delta \mathrm{WV}=$ mechanical efficiency; $\Delta \mathrm{HR} / \Delta \mathrm{VO} \mathrm{O}^{2}=$ cardiovascular efficiency; $\triangle \mathrm{VE} / \Delta \mathrm{V} C \mathrm{O}^{2}=$ ventilatory efficiency; $\Delta \mathrm{VT} /$ $\Delta \mathrm{InVE}=$ linearized $(\mathrm{In})$ berthing pattern. 
Table 3 - Dynamic physiologic responses to the incremental shuttle walk test according to age

\begin{tabular}{|c|c|c|c|c|}
\hline & \multicolumn{4}{|c|}{ Age group (years) } \\
\hline & $40-49(n=26)$ & $50-59(n=28)$ & $60-69(n=26)$ & $\geq 70(n=20)$ \\
\hline$\Delta \mathrm{VO} 2 / \Delta \mathrm{WV}\left(\mathrm{mL} \cdot \mathrm{min}^{-1} \cdot \mathrm{km} \cdot \mathrm{h}^{-1}\right)$ & $288 \pm 84$ & $254 \pm 71$ & $258 \pm 51$ & $215 \pm 69^{*}$ \\
\hline$\Delta \mathrm{V} 02 / \Delta \mathrm{WV}\left(\mathrm{mL} \cdot \mathrm{min}^{-1} \cdot \mathrm{kg}^{-1} \cdot \mathrm{km} \cdot \mathrm{h}^{-1}\right)$ & $4.11 \pm 1.64$ & $3.33 \pm 1.15$ & $3.60 \pm 0.97$ & $2.69 \pm 1.02^{\star}$ \\
\hline$\Delta \mathrm{HR} / \Delta \mathrm{VO2}$ (beat.min ${ }^{-1}$.L.min ${ }^{-1}$ ) & $46 \pm 15$ & $42 \pm 14$ & $40 \pm 12$ & $41 \pm 22$ \\
\hline$\Delta \mathrm{VE} / \Delta \mathrm{VCO2}\left(\mathrm{L} \cdot \mathrm{min}^{-1} \cdot\right.$ L. $\left.\mathrm{min}^{-1}\right)$ & $28 \pm 4$ & $28 \pm 4$ & $29 \pm 4$ & $28 \pm 4$ \\
\hline$\Delta V T / \Delta \operatorname{lnVE}$ & $0.66 \pm 0.33$ & $0.67 \pm 0.24$ & $0.64 \pm 0.22$ & $0.56 \pm 0.22$ \\
\hline
\end{tabular}

Note: ${ }^{\star} \mathrm{p}<0.05$ vs. $40-49$ years. $\Delta \mathrm{VO}_{2} / \Delta \mathrm{WV}=$ mechanical efficiency; $\Delta \mathrm{HR} / \Delta \mathrm{VO}_{2}=$ cardiovascular efficiency; $\Delta \mathrm{VE} / \Delta \mathrm{VCO}{ }_{2}=$ ventilatory efficiency; $\Delta \mathrm{VT} / \Delta \mathrm{InVE}=$ linearized (In) berthing pattern.

Table 4 - Dynamic physiological responses and peak oxygen uptake to the incremental shuttle walk test in obese and nonobese participants

\begin{tabular}{|c|c|c|}
\hline & \multicolumn{2}{|c|}{ Body mass index $\left(\mathrm{kg} . \mathrm{m}^{-2}\right)$} \\
\hline & $<30(n=70)$ & $\geq 30$ up to $35(n=30)$ \\
\hline$\Delta \mathrm{VO}_{2} / \Delta \mathrm{WV}\left(\mathrm{mL} \cdot \mathrm{min}^{-1} \cdot \mathrm{km} \cdot \mathrm{h}^{-1}\right)$ & $263 \pm 70$ & $247 \pm 64$ \\
\hline$\Delta \mathrm{V} \mathrm{O}^{2} / \Delta \mathrm{WV}\left(\mathrm{mL} \cdot \mathrm{min}^{-1} \cdot \mathrm{kg}^{-1} \cdot \mathrm{km}^{-\mathrm{h}^{-1}}\right)$ & $3.84 \pm 1.21$ & $2.94 \pm 0.90^{\star}$ \\
\hline$\Delta \mathrm{HR} / \Delta \mathrm{V} \mathrm{O}^{2}$ (beat.min ${ }^{-1}$.L.min ${ }^{-1}$ ) & $41 \pm 15$ & $44 \pm 13$ \\
\hline$\Delta \mathrm{VE} / \Delta \mathrm{VCO}{ }_{2}\left(\mathrm{~L}^{2} \cdot \mathrm{min}^{-1} \cdot\right.$ L. $\left.\cdot \mathrm{min}^{-1}\right)$ & $28 \pm 4$ & $30 \pm 4$ \\
\hline$\Delta \mathrm{VT} / \Delta \mathrm{InVE}$ & $0.67 \pm 0.26$ & $0.57 \pm 0.20^{\star}$ \\
\hline Peak VO ${ }_{2}\left(\mathrm{~mL} \cdot \mathrm{min}^{-1} \cdot \mathrm{kg}^{-1}\right)$ & $25 \pm 6$ & $19 \pm 5^{\star}$ \\
\hline
\end{tabular}

Note: ${ }^{*} \mathrm{p}<0.05$ vs. non-obese participants; $\Delta \mathrm{VO}_{2} / \Delta \mathrm{WV}=$ mechanical efficiency; $\Delta \mathrm{HR} / \Delta \mathrm{VO}_{2}=$ cardiovascular efficiency; $\Delta \mathrm{VE} / \Delta \mathrm{VCO}{ }_{2}=$ ventilatory efficiency; $\Delta \mathrm{VT} / \Delta \mathrm{InVE}=$ linearized (In) berthing pattern; $\mathrm{VO}_{2}=$ oxygen uptake.
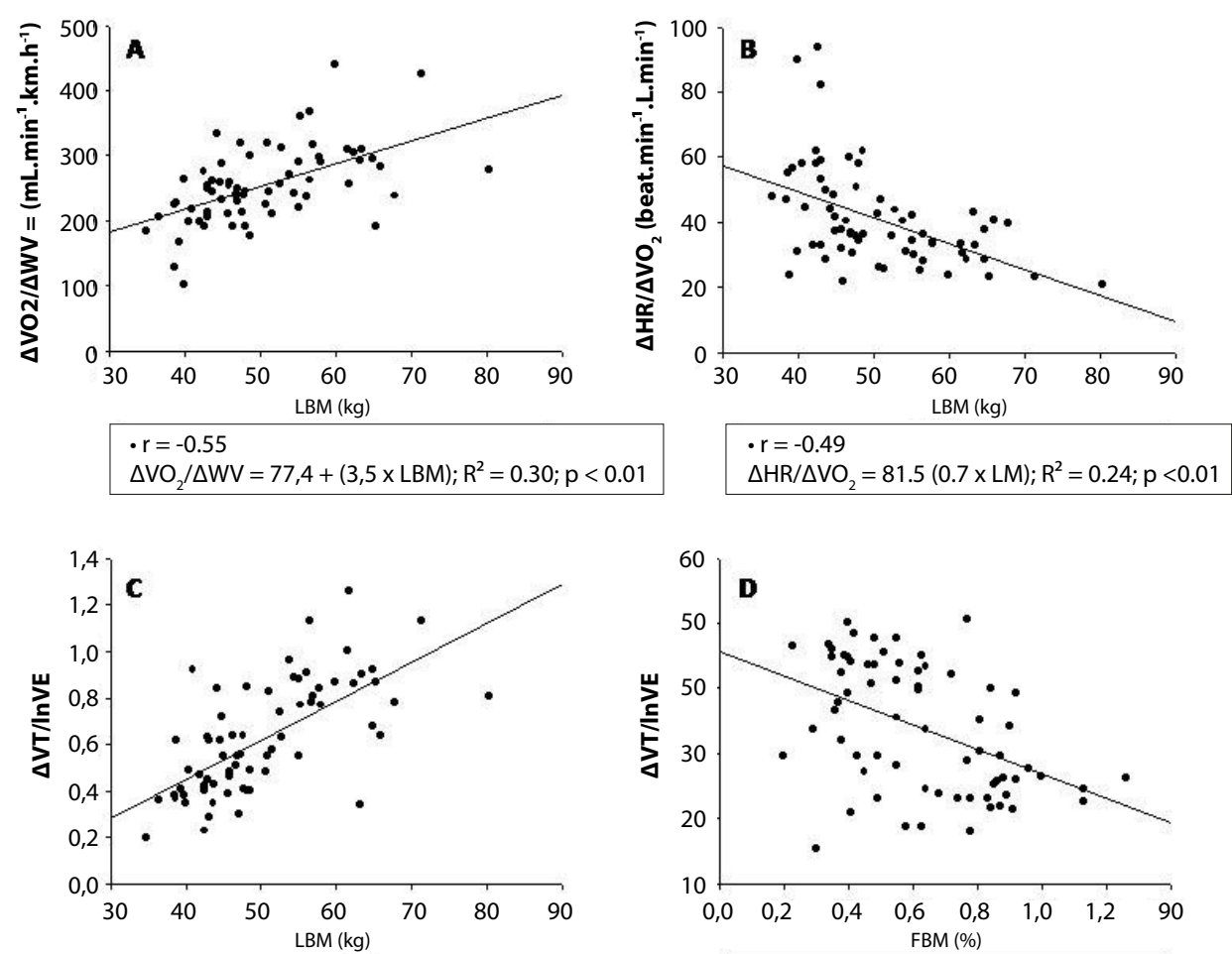

$\cdot r=-0.66$

$\Delta \mathrm{VT} / \mathrm{InVE}=-0.21+(0,01 \times \mathrm{LBM}) ; \mathrm{R}^{2}=0.43 ; \mathrm{p}<0.01$

$\cdot r=-0.45$

$\Delta \mathrm{VT} / \mathrm{InVE}=1.001-\left(0.01 \times \mathrm{FBM} ; \mathrm{R}^{2}=0.20 ; \mathrm{p}<0.01\right.$

Figure 1 - Significant correlations among fat (FBM) and lean (LBM) body masses, and mechanical efficiency $(\triangle V 02 / \Delta W V)$, cardiovascular efficiency $(\triangle \mathrm{HR} / \Delta \mathrm{V} 02)$ and breathing pattern ( $\triangle \mathrm{VT} / \Delta \mathrm{InVE})$. 
Peak $\mathrm{VO}_{2}$ at the end of the ISWT showed high correlation with $\Delta \mathrm{VO}_{2} / \Delta \mathrm{WV}\left(\mathrm{r}=0.83\right.$ and $\mathrm{R}^{2}=0.70$; $\mathrm{p}<0.001)$, weak correlation with $\Delta \mathrm{HR} / \Delta \mathrm{VO}_{2}(\mathrm{r}=-0.41$ and $\left.\mathrm{R}^{2}=0.17 ; \mathrm{p}<0.001\right)$, and moderate correlation with $\Delta \mathrm{VT} / \Delta \operatorname{lnVE}\left(\mathrm{r}=0.62\right.$ and $\left.\mathrm{R}^{2}=0.40 ; \mathrm{p}<0.001\right)$. After multiple regression analysis, only $\Delta \mathrm{VT} / \Delta \operatorname{lnVE}$ was determined for weight and height $\left(\mathrm{R}^{2}=0.07\right)$.

\section{Discussion}

This study evaluated dynamic physiological responses during walking at progressive velocity in healthy middle-aged and older men and women. Our results constitute a useful characterization of normal responses for important physiological indices of exercise capacity in this age group considering the lack of information in the literature regarding field walking tests.

We observed the influence of age only on $\Delta \mathrm{VO}_{2} /$ $\Delta \mathrm{WV}$. The decline in aerobic capacity seen in older age was associated with a decreased mechanical efficiency, especially in septuagenarians'. These changes may be due to a gradual reduction in muscle mass, muscle strength and aerobic capacity that typically occurs in parallel with aging. We have also observed a high positive correlation between peak $\mathrm{VO}_{2}$ at the end of the ISWT and $\Delta \mathrm{VO}_{2} / \Delta \mathrm{WV}$ in the present study. Other studies have reported weak correlations between $\mathrm{VO}_{2}$ and aerobic efficiency on the cycle ergometer (3). There is some controversy in the literature on this issue. This dynamic relationship has been described as independent of age, sex and level of physical activity. For example, Neder et al. (3) did not find any influence of age on $\Delta \mathrm{VO}_{2} / \Delta \mathrm{WV}$ in a randomized study involving sedentary individuals in a wide age range (20 to 80 years). Our results stand in contrast to this, however, on the other hand, reinforces the findings in the literature when CPET was performed on a treadmill. Jones et al. (23) showed that the cost of walking was higher and usual walking velocity was lower in older women than in their younger counterparts. The higher muscle co-activation of agonist and antagonist muscles during the walking at various speeds may partially explain the elevated cost of walking (24). The higher energy costs in older individuals during exercise on a treadmill, in turn, results in reduced cardiovascular efficiency of $8 \%$ according to the findings of Woo et al. (25). Moreover, aging has been associated with a decrease in muscle capillarization and mitochondrial enzyme activity. Reduced oxidative capacity may lead to premature or excessive lactate accumulation and an increase in the oxygen cost of exercise (26). Additional explanations include changes in cardiac function, skeletal muscle blood flow from a decrease in capillary content and density, nutritional status, and hormone levels in parallel with aging (27). Our results reinforce the findings of the literature, although we were unable to find studies that evaluated the $\Delta \mathrm{VO}_{2} / \Delta \mathrm{WV}$ relationship during the ISWT.

In the study by Neder et al. (3) performed on a cycle ergometer, age-dependent changes in cardiovascular efficiency, ventilator efficiency and breathing pattern were observed. This may be attributed to physiological differences between walking (ISWT) and cycling. Although peak values of $\mathrm{VO}_{2}, \mathrm{VE}$, and $\mathrm{HR}$ as well as HR and breathing reserves were described as similar between ISWT and cycling in patients with chronic obstructive pulmonary disease and in healthy subjects (8), the ISWT evoked a lower peak $\mathrm{VCO}_{2}$ and blood lactate concentration than the incremental cycle ergometer test, suggesting a reduced contribution from nonaerobic metabolism to energy production. Besides that, the act of pedaling is not as familiar as walking, especially for older individuals. Thus, the age-dependent changes in cardiovascular efficiency, ventilatory efficiency and breathing pattern observed in older individuals could be influenced by the exercise modality. Therefore, it is reasonable to assume that walking is more representative of daily life than cycling, and it could alter the outcome of the cycle ergometer test (28).

Also on the cycle ergometer test in a ramp protocol, women presented less favorable values of $\Delta \mathrm{HR} /$ $\Delta \mathrm{VO}_{2}, \Delta \mathrm{VE} / \Delta \mathrm{VCO}_{2}$ and $\Delta \mathrm{VT} / \Delta \operatorname{lnVE}(3)$. Our results were different, considering that we did not observe any sex-related differences in the studied dynamic relationships despite the lower values for peak $\mathrm{VO}_{2}$. Reinforcing our findings, Woo et al. (25) evaluated young (20 - 30 years) and older adults (65 to 79 years) in a ramp CPET performed on a treadmill and did not find any sex-related differences in exercise efficiency. Sex influenced the $\Delta \mathrm{VE} / \Delta \mathrm{VCO}_{2}$ relationship in a ramp CPET performed on a cycle ergometer (3). However, in a multiple regression analysis, only age remained an independent predictor for this relationship, independent of sex (3). Davis et al. (29) evaluated twenty-eight healthy men and women that performed CPETs on treadmill and cycle ergometer on different days. In men, there was no significant 
difference between exercises for ventilatory efficiency but the opposite was observed in the women since different values were observed on the treadmill. The authors conclude that healthy women demonstrate an exercise type dependency for the ventilatory efficiency. The ventilatory response (VE) for the same increase in metabolic rate is greater when the partial pressure of carbon dioxide in arterialized venous blood $\left(\mathrm{PavCO}_{2}\right)$ is lower than normal (30). Thus, less efficient ventilatory response in women, observed in incremental tests in cycle ergometer, can be justified by their lower levels of PavCO2 at rest compared to men (3). However, this exaggerated ventilatory response was not found in our study. The ISWT can be considered a submaximal test in many cases, as it is not allowed to run. For this reason, the so-called "ceiling effect" may occur, resulting in decreased production of lactate, thereby flattening the linear behavior of $\triangle \mathrm{VE} / \triangle \mathrm{VCO}_{2}$. But the test in cycle ergometer are symptom-limited, therefore, have no "ceiling effect". Finally, we believe that this difference between the tests is the cause of the discrepancy of the results regarding the ventilatory efficiency in women.

In the present study, obese participants presented worse values of $\Delta \mathrm{VO}_{2} / \Delta \mathrm{WV}$ and $\Delta \mathrm{VT} / \Delta \ln V E$. Our results are consistent with previous results widely reported in the literature (31). Obesity increases the oxygen demand for any given task. Beginning with the basal metabolism, which is increased in comparison with eutrophic subjects (32). The increased cardiovascular demand is not accompanied by increased heart, blood vessels, lungs and muscles. Consequently, there are higher cardiovascular and ventilatory demands in obese individuals (2). The $\Delta \mathrm{VO}_{2} / \Delta \mathrm{W}$ relationship has been described as displaced upward with no changes in the slope of the regression line (33). Our results were different. There wasn't upward displacement of the $\Delta \mathrm{VO}_{2} / \Delta \mathrm{W}$ relationship, as no significant differences in the y-intercept (data not shown) were observed, however, there was a significant reduction in the slope of the linear regression compared to normal weight and overweight participants. This difference may be attributed to the absence of weight bearing on the cycle ergometer. Certainly, during the walking at progressive velocity there is greater demand for anaerobic metabolism in obese participants. Since the glycolytic fibers are less efficient in metabolizing oxygen, there was a shallow $\Delta \mathrm{VO}_{2} / \Delta \mathrm{WV}$ relationship. Additionally, the obese participants were less fit than the others, which contribute to the flattening of the relationship behavior. The tachypneic breathing pattern observed for the obese participants reinforces this hypothesis. Instead, the LBM presented positively influence on three of the four studied dynamic relationships. These results are likely to be related to the well-known stroke volume-body mass relationship and to the underlying relationship between lean body mass and regular physical activity (34).

The present study has limitations that should be discussed. The dynamic relationships are more clearly defined in ramp CPETs. It would be not operationally easy to simulate a ramp protocol in a field test. However, the ISWT is a rapidly incremental test and its load increments in stages up to a minute may generate physiological responses that allow the assessment of dynamic relationships (2). The original ISWT protocol was developed for patients with respiratory diseases and does not allow individualization. This may have generated very small load increments for some participants. However, this should not have happened oftentimes, as we excluded those involved in regular physical activity (14). In fact, an objective assessment of the level of physical activity in daily life would be very informative. Although sedentary and physically inactive individuals had been included in our study, we do not believe that the very low volume of physical activity has significantly influenced the submaximal physiological responses in our study. Thirty percent of our sample was composed of obese participants; however, they did not present cardiovascular, pulmonary, metabolic or musculoskeletal co-morbidities.

The results of this study contribute to the physiotherapist clinical practice, they show that through ISWT is possible to perform the analysis of dynamic physiological dynamics in response to the test and this knowledge may be useful and allows better interpretation of the walking ability of patients with or without chronic diseases affecting exercise capacity in middle-aged and older adults.

\section{Conclusion}

We conclude that the decline in aerobic capacity seen with older age was associated with a decreased mechanical efficiency, especially in septuagenarians'. As in the older population, female gender was associated with a decreased aerobic capacity, but was not associated with a similar difference in dynamic 
relationships. Body composition plays important role in the dynamic physiology of walking. In addition, our results provide values of dynamical physiological responses during walking in healthy adults, enabling better interpretation of the walking ability of middle-aged and older adults with or without chronic diseases that affect exercise capacity.

\section{References}

1. ERS Task Force, Palange P, Ward SA, Carlsen KH, Casaburi R, Gallagher CG, et al. Recommendations on the use of exercise testing in clinical practice. Eur Respir J. 2007;29(1):185-209.

2. Wasserman K, Hansen J, Sue DY, Whipp BJ, Casaburi R. Principles of exercise testing and interpretation. 4th ed. Philadelphia: Lippincott Wiliams \& Wilkins; 2005. 576 p.

3. Neder JA, Nery LE, Peres C, Whipp BJ. Reference values for dynamic responses to incremental cycle ergometry in males and females aged 20 to 80. Am J Respir Crit Care Med. 2001;164(8 Pt 1):1481-6.

4. Sperandio EF, Alexandre AS, Yi LC, Poletto PR, Gotfryd AO, Vidotto MC, et al. Functional aerobic exercise capacity limitation in adolescent idiopathic scoliosis. Spine J. 2014;14(10):2366-72.

5. Singh SJ, Morgan MD, Hardman AE, Rowe C, Bardsley PA. Comparison of oxygen uptake during a conventional treadmill test and the shuttle walking test in chronic airflow limitation. Eur Respir J. 1994;7(11):2016-20.

6. Sperandio EF, Arantes RL, Matheus AC, Silva RP, Lauria VT, Romiti M, et al. Intensity and physiological responses to the 6-minute walk test in middle-aged and older adults: a comparison with cardiopulmonary exercise testing. Braz J Med Biol Res. 2015;48(4):349-53.

7. Sperandio EF, Arantes RL, Silva RPd, Matheus AC, Lauria VT, Bianchim MS, et al. Screening for physical inactivity among adults: the value of distance walked in the six-minute walk test. A cross-sectional diagnostic study. Sao Paulo Med J. 2016;134(1):56-62.

8. Dourado VZ, Guerra RL, Tanni SE, Antunes LCO, Godoy I. Physiological responses to the incremental shuttle walk test in healthy adults. Eur Respir J. 2011;38(Suppl 55):2180.
9. Sociedade Brasileira de Pneumologia e Tisiologia. Diretrizes para testes de função pulmonar. J Pneumol. 2002;28(Supl. 3):1-82.

10. Thomas S, Reading J, Shephard RJ. Revision of the Physical Activity Readiness Questionnaire (PAR-Q). Can J Sport Sci. 1992;17(4):338-45.

11. Ferris BG. Epidemiology Standardization Project (American Thoracic Society). Am Rev Respir Dis. 1978;118(6 Pt 2):1-120.

12. Thompson PD, Arena R, Riebe D, Pescatello LS. ACSM's new preparticipation health screening recommendations from ACSM's guidelines for exercise testing and prescription, ninth edition. Curr Sports Med Rep. 2013;12(4):215-7.

13. Barros MVG, Nahas MV. Reprodutibilidade (testereteste) do questionário internacional de atividade física (QIAF-Versão 6): um estudo piloto com adultos no Brasil. Rev Bras Ciênc e Mov. 2000;8(1):23-6.

14. American College of Sports Medicine Position Stand. The recommended quantity and quality of exercise for developing and maintaining cardiorespiratory and muscular fitness, and flexibility in healthy adults. Med Sci Sports Exerc. 1998;30(6):975-91.

15. Kyle UG, Bosaeus I, Lorenzo AD, Deurenberg P, Elia M, Manuel Gomez J, et al. Bioelectrical impedance analysis-part II: utilization in clinical practice. Clin Nutr. 2004;23(6):1430-53.

16. Kyle UG, Genton L, Karsegard L, Slosman DO, Pichard C. Single prediction equation for bioelectrical impedance analysis in adults aged 20--94 years. Nutrition. 2001;17(3):248-53.

17. Miller MR, Hankinson J, Brusasco V, Burgos F, Casaburi $\mathrm{R}$, Coates A, et al. Standardisation of spirometry. Eur Respir J. 2005;26(2):319-38.

18. Pereira CAC, Sato T, Rodrigues SC. Novos valores de referência para espirometria forçada em brasileiros adultos de raça branca. J Bras pneumol. 2007;33(4):397-406.

19. Singh SJ, Puhan MA, Andrianopoulos V, Hernandes NA, Mitchell KE, Hill CJ, et al. An official systematic review of the European Respiratory Society/American Thoracic Society: measurement properties of field walking tests in chronic respiratory disease. Eur Respir J. 2014;44(6):1447-78. 
20. Singh SJ, Morgan MD, Scott S, Walters D, Hardman AE. Development of a shuttle walking test of disability in patients with chronic airways obstruction. Thorax. 1992;47(12):1019-24.

21. Lanza FC, Zagatto EP, Silva JC, Selman JPR, Imperatori TBG, Zanatta DJM, et al. Reference Equation for the Incremental Shuttle Walk Test in Children and Adolescents. J Pediatr. 2015;167(5):1057-61.

22. Mukaka MM. Statistics corner: A guide to appropriate use of Correlation coefficient in medical research. Malawi Med J. 2012;24(3):69-71.

23. Jones LM, Waters DL, Legge M. Walking speed at selfselected exercise pace is lower but energy cost higher in older versus younger women. J Phys Act Health. 2009;6(3):327-32.

24. Peterson DS, Martin PE. Effects of age and walking speed on coactivation and cost of walking in healthy adults. Gait Posture. 2010;31(3):355-9.

25. Woo JS, Derleth C, Stratton JR, Levy WC. The influence of age, gender, and training on exercise efficiency. J Am Coll Cardiol. 2006;47(5):1049-57.

26. Russ DW, Lanza IR. The Impact of Old Age on Skeletal Muscle Energetics: Supply and Demand. Curr Aging Sci. 2011;4(3):234-47.

27. Lakatta EG. So! What's aging? Is cardiovascular aging a disease? J Mol Cell Cardiol. 2015;83:1-13.

28. Fotheringham I, Meakin G, Punekar YS, Riley JH, Cockle SM, Singh SJ. Comparison of laboratory- and fieldbased exercise tests for COPD: a systematic review. Int J Chron Obstruct Pulmon Dis. 2015;10:625-43.
29. Davis JA, Tyminski TA, Soriano AC, Dorado S, Costello $\mathrm{KB}$, Sorrentino KM, et al. Exercise test mode dependency for ventilatory efficiency in women but not men. Clin Physiol Funct Imaging.. 2006;26(2):72-8.

30. Oren A, Wasserman K, Davis JA, Whipp BJ. Effect of $\mathrm{CO} 2$ set point on ventilatory response to exercise. J Appl Physiol Respir Environ Exerc Physiol. 1981;51(1):185-9.

31. Arena R, Cahalin LP. Evaluation of cardiorespiratory fitness and respiratory muscle function in the obese population. Prog Cardiovasc Dis. 2014;56(4):457-64.

32. Wilms B, Ernst B, Thurnheer M, Weisser B, Schultes B. Correction factors for the calculation of metabolic equivalents (MET) in overweight to extremely obese subjects. Int J Obes (Lond). 2014;38(11):1383-7.

33. Lafortuna CL, Agosti F, Busti C, Galli R, Sartorio A. The energy cost of cycling and aerobic performance of obese adolescent girls. J Endocrinol Invest. 2009;32(8):647-52.

34. Dourado VZ, Guerra RL, Tanni SE, Antunes LC, Godoy I. Reference values for the incremental shuttle walk test in healthy subjects: from the walk distance to physiological responses. J Bras Pneumol. 2013;39(2):190-7.

Received in $03 / 22 / 2016$

Recebido em 22/03/2016

Approved in 04/04/2017

Aprovado em 04/04/2017 